\title{
Development and Physicochemical Characterization of Desonide-Loaded Nanocapsule Suspensions
}

\author{
M. B. Antonow, ${ }^{1,2}$ R. Lorenzoni, ${ }^{1,3}$ G. M. Barbosa, ${ }^{1}$ A. F. Ourique, ${ }^{1}$ \\ P. Gomes, ${ }^{1}$ and R. P. Raffin ${ }^{1}$ \\ ${ }^{1}$ Programa de Pós-Graduação em Nanociências, Centro Universitário Franciscano, Santa Maria, RS, Brazil \\ ${ }^{2}$ Programa de Pós-Graduacão em Nanotecnologia Farmacêutica, Faculdade de Farmácia, \\ Universidade Federal do Rio Grande do Sul, Porto Alegre, RS, Brazil \\ ${ }^{3}$ Programa de Pós-Graduacão em Ciências Farmacêuticas, Faculdade de Farmácia, Universidade Federal do Rio Grande do Sul, \\ Porto Alegre, RS, Brazil \\ Correspondence should be addressed to R. P. Raffin; reraffin@gmail.com
}

Received 15 May 2016; Revised 3 August 2016; Accepted 11 August 2016

Academic Editor: Peter Majewski

Copyright (C) 2016 M. B. Antonow et al. This is an open access article distributed under the Creative Commons Attribution License, which permits unrestricted use, distribution, and reproduction in any medium, provided the original work is properly cited.

Desonide is a topical corticosteroid that has been used for more than 30 years; however, its prolonged use can induce several side effects, affecting dermis and epidermis. The present work consists of development desonide-loaded nanocapsule suspensions (DNC) using different polymers (Eudragit S100 ${ }^{\circledR}$ or Eudragit L100 ${ }^{\circledR}$ ) and desonide-loaded lipid-core nanocapsules (D-LNC). They were formulated by interfacial deposition using the preformed polymer method and all formulations showed negative zeta potential and adequate nanotechnological characteristics (particle size $161-202 \mathrm{~nm}$, polydispersity index $<0.20$ ). Simple and sensitive methods using high-performance liquid chromatography (HPLC) were developed to quantify desonide in LNC and to study its release kinetics. The method was linear, specific, precise, and exact and therefore can be applied in quantification of D-NC and D-LNC. We evaluated in vitro methods for drug release (dissolution, Franz diffusion cells, and dialysis sac) and we use mathematical models (monoexponential, biexponential, and Korsmeyer-Peppas) to show release kinetics from this system.

\section{Introduction}

Desonide is a synthetic nonfluorinated corticosteroid and has been widely used as a topical treatment of inflammation caused by a number of conditions such as allergic reactions and psoriasis for more than 30 years $[1,2]$. Topical corticosteroids were introduced in medicine for 50 years and represent a landmark in dermatologic therapy, have fast action, and are the most effective anti-inflammatory drugs available, by promoting systematic improvement of clinical manifestations $[3,4]$. Its clinical efficacy is mainly due to its anti-inflammatory, vasoconstrictive, proliferative, immunosuppressive action. Because of the risks of tolerance and local and systemic adverse effects, these drugs should be used in amounts, frequency, and duration of application minimum necessary for the required clinical efficacy [5-7]. The nanoencapsulation can be capable of minimizing this adverse effects; however, until now no one studied the development of desonide-loaded in nanoparticles.

In this context, the nanotechnology became an important tool on the pharmaceutical development promoting significant changes in the market of medicine production [8]. The nanostructured carrier systems have dimensions between 10 and $1000 \mathrm{~nm}$ and differ according to the qualitative composition and organization at the molecular level [9]. Loading of therapeutic agents into polymeric nanoparticles provides several benefits, including drug protection from degradation or premature metabolism, as well as sustained release and maintenance of plasma drug concentrations at therapeutic levels, besides having their toxicity reduced and/or efficacy increased $[10,11]$. Studies have shown that the nanoparticles have a tendency to accumulate in inflamed tissues, providing new perspectives for action of anti-inflammatory drugs [12]. The nanoparticles can accumulate in inflamed tissues due to 
the greater microvascular permeability in those sites. Thus, indomethacin-loaded nanocapsules produced an increased anti-inflammatory efficacy in rat models of inflammation (acute and chronic edema) compared with free indomethacin [13]. Furthermore, the drugs loaded in nanocapsules are capable of the maintenance of high levels of prostaglandin over longer periods, showing good results for control of inflammatory reactions [14].

The polymeric nanoparticles have been described in the literature in order to reduce adverse effects and systemic absorption pertinent to corticosteroids [15-20]. For nanoparticles of type nanocapsules, the polymeric wall plays a predominant role in protecting the active substances incorporated and probably in the release profile [21, 22]; crystallinity and hydrophobic nature of polymer are key factors in determining the rate of in vitro degradation from nanoparticles [23]. The polymers commonly used are biodegradable polyesters, especially poly-e-caprolactone (PCL), poly(lactide) (PLA), and poly(lactide-co-glycolide) (PLGA). Eudragit can also be used as may other polymers such as poly(alkylcyanoacrylate) (PACA) [22]. The polymers of interest in this work, PCL [24-27], Eudragit S100 [28], Eudragit $\mathrm{RS}^{\circledR}$, or Eudragit L100-55 ${ }^{\circledR}[29,30]$, have been described in the development of nanocapsules.

PCL is one polymer of the great interest in medicine due to the nontoxicity, slow degradation rate, and high permeability to many drugs and therefore has been widely used as a drug delivery vehicle $[31,32]$. Eudragits are synthetic copolymers of dimethylaminoethyl methacrylates, methacrylic acid, and methacrylic acid esters in varying ratios. Eudragit L100 and Eudragit S100 are anionic polymers with chemical name based on polymeric ratios of poly(methacrylic acid, methyl methacrylate) $1: 1$ and $1: 2$, respectively. These polymers have pH-dependent solubility, Eudragit L100 dissolving at pH 6.0 and Eudragit S100 dissolving at pH 7.0 are commonly used for sustained release formulations [33].

Lipid-core nanocapsules (LNC), a specific type of nanoparticle which uses PCL as the polymer [34], have several applications such as providing sustained release of drugs [20]; the penetration of this nanoparticle into the skin showed retention at the outermost layers of the skin, independent of the drug penetration profile [35] and has been described as an intelligent way for immediate and sustained drug delivery for skin disease treatment [27]. Moreover, LNC have shown capacity to encapsulate topical corticosteroids with mometasone furoate, suitable for prolonged treatment of skin disorders [36], dexamethasone, promoted increase of drug delivered into viable epidermis [37], betamethasone dipropionate, and dithranol, and provided decreased irritation potential of these drugs [38, 39]. LNC contains a mixture of a medium chain triglyceride (oil) and sorbitan monostearate (solid) in the core. In the case, the release of drug from lipid-core nanocapsule can be controlled varying the components of the core or polymer wall $[19,20]$.

In vitro drug release studies are important tool to assess the ability of the nanoparticles suspensions to control the drug release compared to solutions containing drugs not encapsulated. One of the biggest obstacles is that the in vitro drug release involves the separation of the drug still encapsulated in the particle from that drug free of particle into release medium $[30,40]$. Therefore, in most techniques the monitoring of the drug release is performed by a physical separation of the nanoparticle from the release medium to discriminate the unreleased and released drug [41]. According to $\mathrm{Xu}$ et al. [42] the methods for drug release from nanoparticles can be classified into two categories: sample and separation methods (ultrafiltration, ultracentrifugation, or centrifugal ultrafiltration techniques), like dissolution method [43] and membrane diffusion methods, such as dialysis sac $[16,44]$ and Franz diffusion cells $[27,36]$. The most used technique is dialysis sac, which consists in employment of a selective membrane. The drug release in medium inside the dialysis bag to pass through the membrane is according to the laws of diffusion and the principle of dialysis [45].

Thus, an appropriate in vitro release study is often difficult to conduct and the results reflect complex kinetics of several simultaneous processes with hard interpretation [41]. Mathematical models were applied to the release profiles to facilitate the interpretation of results. The monoexponential and biexponential models have been proposed to describe the drug release from nanocapsules $[20,26,30,43,44]$. The biexponential model is characterized by biphasic release with burst effect corresponds to initial release period, attributed either to the desorption of the drug situated on the nanocapsules surface or to the degradation of the polymeric wall surrounding the oily core containing the drug, and second phase corresponds to the diffusion of the drug molecules from oil core $[23,46]$.

Investigations of drug release often provide important information about the structure of the nanoparticles and the drug encapsulated physicochemical relationships for developing successful formulations [47]. In the present work desonide-loaded nanocapsules were developed using Eudragit L100 described as copolymer 1:1 and Eudragit S100 copolymer 1:2 and, desonide-loaded lipid-core nanocapsules, in order to assess the influence of the polymeric wall on the encapsulation efficiency of desonide, measurements of size, polydispersity, zeta potential, and $\mathrm{pH}$ analysis. In vitro release of desonide was examined by dialysis sac; Franz diffusion cells and dissolution methods and mechanism of drug release were investigated using mathematical equations.

\section{Materials and Methods}

2.1. Materials. Desonide was supplied by Deg (Brazil), (purity 97,0-103,0\%). Sorbitan monostearate and poly $(\varepsilon$ caprolactone) (Mw 42500) were obtained from Sigma Aldrich $^{\circledR}$ (USA), Eudragit S100 and Eudragit L100 were obtained from Degussa (Darmstadt, Germany), and caprylic/ capric triglyceride and polysorbate 80 were obtained from Via Farma $^{\circledR}$ (Brazil). All other solvents used were of analytical or pharmaceutical grade.

2.2. Preparation of Formulations. Desonide-loaded nanocapsules (D-NC) and loaded lipid-core nanocapsules (D-LNC) were prepared using the methodology of as previously 
described [34] based on the technique from interfacial deposition of preformed polymer [48].

Briefly, the organic phase was composed of polymer (Eudragit S100, Eudragit L100, or Poly( $\varepsilon$-caprolactone), $0.25 \mathrm{~g})$, sorbitan monostearate $(0.0962 \mathrm{~g})$, capric/caprylic triglyceride $(400 \mu \mathrm{L})$, and desonide $(0.0125 \mathrm{~g})$ which were dissolved in acetone $(62.5 \mathrm{~mL})$ at $40^{\circ} \mathrm{C}$. The aqueous phase containing polysorbate $80(0.1925 \mathrm{~g})$ dissolved in water $(125 \mathrm{~mL})$ at $40^{\circ} \mathrm{C}$. Organic phase was injected into an aqueous phase and kept under magnetic stirring for $10 \mathrm{~min}$. The organic solvent was eliminated and the suspension was concentrated under reduced pressure for $25 \mathrm{~mL}$, adjusted in a volumetric flask. The final desonide concentration was $0.5 \mathrm{mg} / \mathrm{mL}$.

Desonide-loaded nanocapsule suspensions using Eudragit S100 were named D-NC-S100 and using Eudragit L100 of D-NC-L100. Desonide-loaded lipid-core nanocapsules were named D-LNC and without drug of LNC.

Moreover, dispersions of the free desonide $(0.5 \mathrm{mg} / \mathrm{mL})$ were prepared with the same experimental conditions described for LNC but omitting the presence of polymer and oil, named free-desonide.

2.3. Chromatographic System. Desonide in the formulation was quantified by high performance liquid chromatography (HPLC) using a method adapted from Nguyen and coworkers [49]. The chromatographic system was YL-Clarity ${ }^{\circledR}$ model YL9100 HPLC System, bomb model YL9110, and detector UV model YL 916, using a column Lichropher ${ }^{\circledR} 100$ RP-18, $250 \mathrm{~mm}, 4 \mathrm{~mm}, 5 \mu \mathrm{m}$, Merck ${ }^{\circledR}$. The mobile phase consisted of methanol $/ 0.2 \mathrm{M}$ acetate buffer, $(60: 40 \mathrm{v} / \mathrm{v}), \mathrm{pH}$ adjusted to 4.0 with acetic acid, and the flow rate was $1.2 \mathrm{~mL} / \mathrm{min}$. The monitoring wavelength was $254 \mathrm{~nm}$ and the injection volume was $10 \mu \mathrm{L}$. All analyses were conducted at room temperature.

2.4. Validation Study. The objective of validation of an analytical experiment is to demonstrate that it is suitable for its intended purpose. Validation was performed following the International Conference on Harmonization (ICH) guidelines [50]. The method was validated by its specificity, linearity, accuracy, precision, and detection and quantification limits.

Standard Solution. Standard solution was prepared at a concentration of $250 \mu \mathrm{g} / \mathrm{mL}$; for this purpose $0.0125 \mathrm{~g}$ of desonide was accurately weighed and transferred to a volumetric flask with $50 \mathrm{~mL}$ of methanol.

Sample Preparation. Desonide was extracted from the LNC by the addition of $10 \mathrm{~mL}$ of methanol in $150 \mu \mathrm{L}$ D-LNC (final concentration $7.5 \mu \mathrm{g} / \mathrm{mL}$ ).

Specificity. The method specificity was evaluated through comparative analysis between solutions containing all the components of the D-LNC and LNC (except the drug).

Linearity. Linearity was verified through 3 curves in 3 consecutive days. Desonide standard solutions were prepared in methanol at $2.5 ; 5.0 ; 7.5 ; 10.0 ; 12.5$; and $15.0 \mu \mathrm{g} / \mathrm{mL}$.
Accuracy. To verify the method accuracy, samples were prepared by mixing the standard solution of desonide and D-LNC. Aliquots of 50, 150, and $250 \mu \mathrm{L}$ of desonide standard solution were transferred into $10 \mathrm{~mL}$ volumetric flasks containing $75 \mu \mathrm{L}$ of D-LNC. The final volume was adjusted to $10 \mathrm{~mL}$ with methanol in a volumetric flask, obtaining desonide concentrations of $5.0 ; 7.5$; and $10.0 \mu \mathrm{g} / \mathrm{mL}$. These studies were performed in triplicate.

Precision. Precision may be considered at two levels: repeatability (intraday precision) and interday precision. The repeatability was evaluated through the analysis of 6 sample solutions (D-LNC) at the concentration of $7.5 \mu \mathrm{g} / \mathrm{mL}$ in one day. Interday precision was calculated using 3 analyses of the samples at 5.0; 7.5; and $10.0 \mu \mathrm{g} / \mathrm{mL}$, on 3 different days. Precision was expressed in relative standard deviation (RSD).

Detection and Quantification Limits. The limit of detection (LOD) is the lowest analyte concentration detectable, whereas the limit of quantification (LOQ) is the lower level of analyte in a sample which can be measured with suitable precision. These parameters were determined mathematically through the relationship between the standard deviation of the curve calibration and slope, accordingly proposed by the ICH [50]. Therefore LOD and LOQ were calculated through (1), using the multiplying factor suggested by the norm of $\mathrm{ICH}$, where $S$ is residual variance due to regression and $b$ is slope:

$$
\begin{aligned}
& \mathrm{LOD}=\frac{s \times 3,3}{b}, \\
& \mathrm{LOQ}=\frac{S \times 10}{b} .
\end{aligned}
$$

2.5. Physicochemical Characterization of Formulations. Were evaluated considering mean diameter, polydispersity index, zeta potential, $\mathrm{pH}$, drug content, and encapsulation efficiencies (EE, \%). For mean diameters the samples were previously diluted in ultrapure water and analyzed by dynamic light scattering (Zetasizer ${ }^{\circledR}$, Nanoseries, UK) to determine the $Z$ average size and polydispersity index (PDI). Zeta potential was determined by electrophoretic mobility (Zetasizer, Nanoseries, UK) from the samples diluted in $\mathrm{NaCl}$ solution $10 \mathrm{mM}(1: 500 \mathrm{v} / \mathrm{v})$. The $\mathrm{pH}$ values of the suspensions were directly measured using a potentiometer B474 (Micronal, Brazil).

The drug content in the D-LNC was assayed by (HPLC) at $254 \mathrm{~nm}$, dissolving the suspensions in methanol $(10 \mathrm{~mL})$. The encapsulation efficiencies (EE, \%) were determined by ultrafiltration-centrifugation (Microcon ${ }^{\circledR}$, MC Millipore $10000 \mathrm{Da}$ ) at $1844 \times \mathrm{g}$ for 5 minutes and quantified by HPLC [51]. The percentage of desonide encapsulated was calculated by the difference between the total (content) and free desonide concentrations (ultrafiltrate) divided by the total desonide content and multiplied by 100 [20].

To determine the simultaneous presence of drug crystals in the formulation, drug contents were measured in not moving sample of each formulation after 30 days. Aliquots for HPLC analyses were performed from the top of the recipient without agitating the formulation [52]. 
2.6. In Vitro Release Study. The in vitro release of freedesonide or desonide-loaded nanocapsule suspensions (DLNC, D-NC-S100, and D-NC-L100) was evaluated using three different methods: dissolution, Franz diffusion cells, and dialysis sac. The release medium was composed of acetate buffer pH 5.5 and $1 \%$ Tween $80^{\circledR}$, maintained under stirring in a water bath of $37.0^{\circ} \mathrm{C}$. The release medium is removed at predetermined time intervals and substituted by fresh medium release to ensure the sink condition. All experiments were conducted with $n=5$. The drug concentration was determined by HPLC according to the method described in the validation study and used standard curve $(y=51.984 x-$ 7.5286, $r=0.9988)$.

2.6.1. Dissolution Method. In this experiment, $1.8 \mathrm{~mL}$ of formulation was put in a $100 \mathrm{~mL}$ beaker containing $50 \mathrm{~mL}$ of release medium. The samples $(2.0 \mathrm{~mL})$ were collected and filtered through a membrane $\left(0.1 \mu \mathrm{m}\right.$, Millipore $\left.{ }^{\circledR}\right)$.

2.6.2. Franz Diffusion Cells. To perform this technique vertical diffusion cell type Franz with receptor compartment with a capacity of about $6.0 \mathrm{~mL}$ and an area diffusion of $3.14 \mathrm{~cm}^{2}$ was used. The membranes used were cellulose acetate with a pore size of $0.45 \mu \mathrm{m}$ Millipore, previously hydrated in ultrapure water for 24 hours before the experiment. After this time, diffusion cells were assembled keeping the membrane in contact with the release medium. The suspensions $(1 \mathrm{~mL})$ were added in the upper part of the membrane; two milliliters aliquots were taken out of the diffusion cells and filtered (0.45 $\mu \mathrm{m}$ Millipore filters).

2.6.3. Dialysis. Dialysis bag composed of cellulose $(25 \times$ $16 \mathrm{~mm}$, cut-off 12000 to $14000 \mathrm{Da}$, Sigma Aldrich) was hydrated in ultrapure water for 24 hours before the experiment. $1.8 \mathrm{~mL}$ of the suspension was added into dialysis sac and put into closed glass flasks containing $50 \mathrm{~mL}$ of the release medium. Aliquots of $2 \mathrm{~mL}$ of release medium were collected and filtered ( $0.45 \mu \mathrm{m}$ Millipore filters).

2.6.4. Particle Size. In order to verify the presence of nanoparticles in the release medium, the mean size of the particles in receptor compartment was determined by Franz diffusion cells and glass flasks by dialysis bag. The samples were withdrawing of release medium and directly measured using dynamic light scattering, at the same time intervals used for the in vitro release studies.

2.6.5. Mathematical Modeling. The release profiles were analyzed using mathematical modeling (MicroMath Scientist ${ }^{\circledR}$ ). The model monoexponential (see (2)) and biexponential (see (3)) were employed to analyze the drug release profiles. The selection of the model was based on the best correlation coefficient and the best model selection criteria (MSC), both provided by the software, and the best graphic adjustment:

$$
\begin{aligned}
& C=C_{0} e^{-k t}, \\
& C=a e^{-k_{1} t}+b e^{-k_{2} t} .
\end{aligned}
$$

The observed release constants are $k, k_{1}$, and $k_{2}$ and the initial concentrations of drug are $C_{0}, a$, and $b$.

The Korsmeyer-Peppas model (see (4)) is generally applied when the drug release mechanism is not known or when there is more than one release mechanism involved $[53,54]$ :

$$
\frac{M_{t}}{M_{\infty}}=k t^{n},
$$

where $M_{t}$ and $M_{\infty}$ are fraction of drug released at time $t$ and infinite time, respectively; $k$ is the release constant and $n$ is the release exponent which is indicative of the transport mechanism. The value of exponent $n$ was determined from initial $60 \%$ of drug released. For sphere geometry, $n \leq 0.43$ indicates Fickian diffusion, $0.43<n<0.85$ indicate an anomalous behavior (non-Fickian kinetics corresponding to coupled diffusion), and $n=0.85$ indicates Case-II transport drug release (relaxational).

2.7. Statistical Analysis. All formulations were prepared and analyzed in triplicate. Results were expressed in mean \pm SD (standard derivation). Analysis of the data was performed using analysis of variance (ANOVA) and Tukey post hoc test (GraphPad Software, Inc., USA). Statistical significance was considered when $p<0.05$.

\section{Results}

3.1. Characterization of Nanocapsule Suspensions. After preparation, all desonide-loaded nanocapsule suspensions (DLNC, D-NC-L100, or D-NC-S100) presented a macroscopic homogeneous appearance, like a milky bluish opalescent liquid. The physicochemical characteristics of the suspensions are presented in Table 1 . The mean diameters of D-NC-S100 and D-NC-L100 are similar (161-163 nm); D-LNC presented bigger diameter $(202 \mathrm{~nm})$. All suspensions presented negative zeta potentials (between -21.7 and $-26.7 \mathrm{mV}$ ) and polydispersity index below 0.2 , suggesting their homogeneity. The EE was dependent on the polymer present in each formulation; however the values observed were similar (between 91.0 and 98.8\%). The higher values of $\mathrm{pH}$ were presented for D-LNC (5.28) compared to those for D-NC-L100 (4.25) and D-NCS100 (3.90). Besides that, drug crystals were not determined in the nanocapsule suspensions after 30 days.

3.2. Validation Study. The validated method was developed for the detection and quantification of D-LNC. The mobile phase consisted of methanol/0.2 $\mathrm{M}$ acetate buffer in the ratio

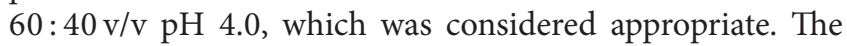
desonide peak (Figure 1(a)) could be observed at retention time of $7.9 \mathrm{~min}$.

Specificity was assessed by comparing desonide chromatogram with LNC chromatogram (Figure 1(b)). The latter did not present any absorption in the retention time of desonide, showing that there were no interferences of the LNC excipients in the detection of desonide.

The linearity of the method was assessed in the concentration range of $2.5-15.0 \mu \mathrm{g} / \mathrm{mL}$. For each concentration, 
TABLE 1: Physicochemical characteristics of desonide-loaded nanocapsule suspensions.

\begin{tabular}{lccc}
\hline Formulation & D-LNC & D-NC-S100 & D-NC-L100 \\
\hline Size $(\mathrm{nm})$ & $202 \pm 4$ & $163 \pm 5$ & $161 \pm 4$ \\
PDI & $0.19 \pm 0.02$ & $0.20 \pm 0.04$ & $0.18 \pm 0.04$ \\
Zeta potential $(\mathrm{mV})$ & $-26.7 \pm 2.0$ & $-21.7 \pm 2.3$ & $-24.0 \pm 3.6$ \\
pH & $5.28 \pm 0.03$ & $3.90 \pm 0.08$ & $4.25 \pm 0.06$ \\
Drug content $(\mathrm{mg} / \mathrm{mL})$ & $0.48 \pm 0.03$ & $0.47 \pm 0.03$ & $0.48 \pm 0.02$ \\
EE $(\%)$ & $97.0 \pm 2.1$ & $98.8 \pm 1.2$ & $91.0 \pm 0.9$ \\
\hline
\end{tabular}

EE: encapsulation efficiency; PDI: polydispersity index.

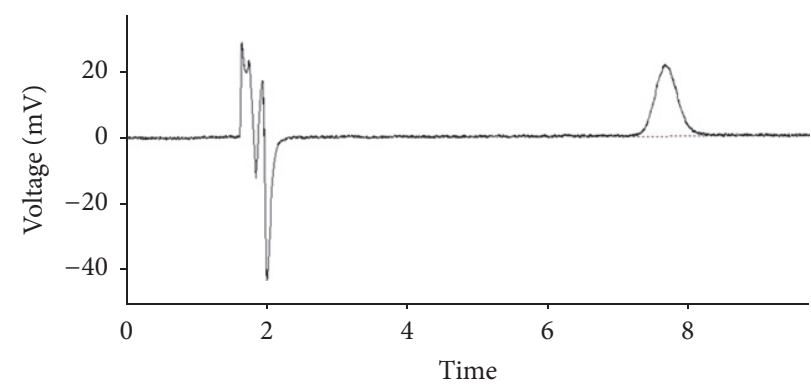

(a)

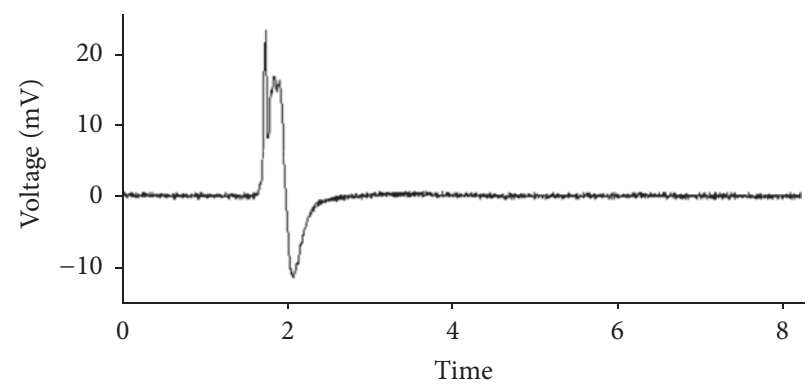

(b)

FIgURE 1: HPLC chromatogram (a) for standard desonide and (b) for LNC.

the relative standard deviation (RSD) was calculated. The calibration curve was obtained by plotting the desonide peak area versus the concentration of standard solution. The linear equation obtained was $y=45.804 x-2.335$ and showed adequate determination coefficient $\left(r^{2}=0.997\right)$. The validity of the assay was verified by analysis of variance. This revealed that the regression equation was linear $\left(F_{\text {calculated }}=1585.32>\right.$ $\left.F_{\text {critical }}=4, P=5 \%\right)$ with no linearity deviation $\left(F_{\text {calculated }}=\right.$ $\left.0.51<F_{\text {critical }}=2.37 ; P=5 \%\right)$. The calculated values for LOD and LOQ were 0.73 and $2.20 \mu \mathrm{g} / \mathrm{mL}$, respectively, indicating adequate sensitivity of the method for the determination the desonide.

The repeatability and interday precision of the method were measured by the determination the relative standard deviation (RSD). The RSD values are shown in the Tables 2 and 3.

In Table 2(a), it can be observe that six values for the repeatability were between 101.2 and $104.8 \%$ and RSD was $1.26 \%$, demonstrating the conformity with the parameters set for the validation of chromatographic methods for drug quantification. The interday precision values are given in Table 2(b); all data are lower than the acceptance criterion of $2 \%$.

The method accuracy is shown in Table 3. The values were considered satisfactory, because recovery rates were between 98 and 102\%, demonstrating conformity with the limits established by ICH [50].

3.3. In Vitro Drug Release Studies. The in vitro drug release from nanocapsule suspensions is one of the most studied parameters in the development of drug-loaded nanoparticles. Many in vitro methods (separation and membrane diffusion
TABLE 2: (a) Values obtained from intraday precision for desonide quantification by HPLC. (b) Values for tests of the interday precision for 3 different days.

(a)

\begin{tabular}{lcc}
\hline Replicates & Desonide quantification (\%) & RSD (\%) \\
\hline 1 & 101.22 & \\
2 & 104.84 & \\
3 & 104.26 & 1.26 \\
4 & 102.58 & \\
5 & 103.70 & \\
6 & 102.83 & \\
\hline
\end{tabular}

(b)

\begin{tabular}{lcc}
\hline Day & Desonide quantification (\%) & RSD (\%) \\
\hline \multirow{2}{*}{ Day 1 } & 103.39 & \\
& 102.77 & 0.48 \\
& 103.73 & \\
Day 2 & 95.28 & \\
& 96.46 & 1.81 \\
& 98.85 & \\
Day 3 & 99.06 & 1.72 \\
& 101.46 & \\
Mean & 98.13 & 0.74 \\
\hline
\end{tabular}

methods) have been used to evaluate the drug release from nanoparticles. With the employment dialysis sac, D-LNC and D-NC-S100 have controlled better release than D-NC-L100 
TABLE 3: Experimental values of the accuracy of the method.

\begin{tabular}{lccc}
\hline Concentration $(\mu \mathrm{g} / \mathrm{mL})$ & Recovery concentration $(\mu \mathrm{g} / \mathrm{mL})$ & Recovery $(\%)$ & RSD $(\%)$ \\
\hline 5.0 & $4.88 \pm 0.05$ & $101.07 \pm 1.52$ \\
7.5 & $7.35 \pm 0.08$ & $100.26 \pm 1.67$ & 0.42 \\
10.0 & $9.98 \pm 0.06$ & $100.92 \pm 1.91$ \\
\hline
\end{tabular}

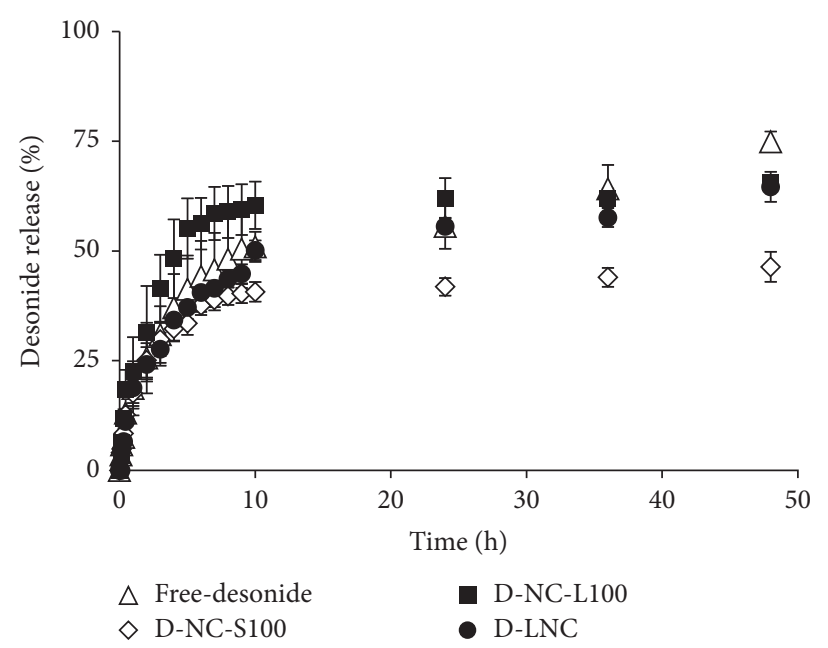

(a)

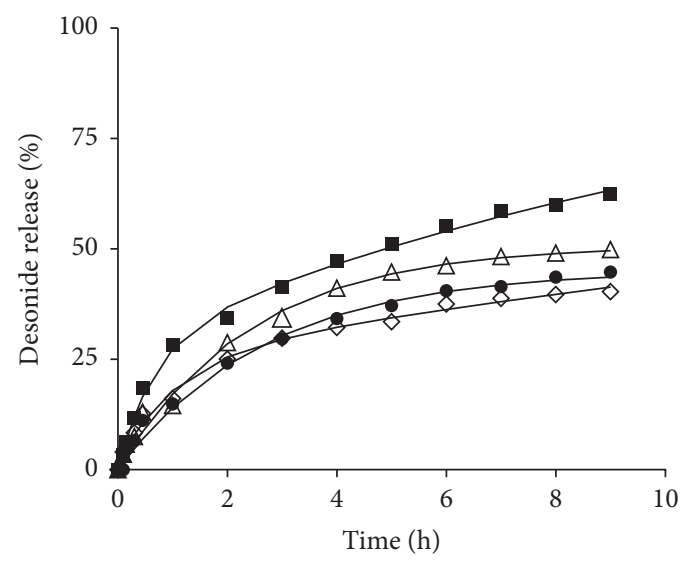

$\begin{array}{lll}\triangle \text { Free-desonide } & \diamond \text { D-NC-S100 } \\ \text { D-LNC } & \square \text { D-NC-L100 }\end{array}$

(b)

Figure 2: (a) Release profile of D-NC-S100, D-NC-L100, D-LNC, and free-desonide using dialysis sac. Statistical significance (Tukey, $p<$ 0.05). (b) The lines correspond to the fitting to the monoexponential equation for D-LNC and free-desonide, biexponential equation for D-NC-L100 and D-NC-S100.

and free-desonide. The D-NC-L100 presented faster release than other suspensions (Figure 2).

The characteristics about drug release profile for desonide-loaded nanocapsules and free-desonide were investigated through the mathematical modeling of the data. The model that best described the release profile for D-LNC and free-desonide was the monoexponential model, with correlation coefficients $(r)$ near 1 and adequate MSC values (Table 4$)$. This model provided release constant $(K)$; this value correlates drug dissolution with time (first order kinetic). D-LNC had higher release constants $\left(K=0.34 \mathrm{~h}^{-1}\right)$ than free desonide $\left(K=0.31 \mathrm{~h}^{-1}\right)$; already the half-life time $\left(t_{1 / 2}\right)$ was higher for free-desonide $(2.36 \mathrm{~h})$ than D-LNC $(2.06 \mathrm{~h})$. On the other hand, the model that best described the release profile for D-NC-S100 and D-NC-L100 formulations was the biexponential model. This model is composed by adding two-term monoexponentials, providing two kinetic constants for release. The observed release constants for the burst phases $\left(K_{1}\right)$ ranged from 1.31 to $1.62 \mathrm{~h}^{-1}$ and the observed rate constant for the sustained phase $\left(K_{2}\right)$ from 0.03 to $0.05 \mathrm{~h}^{-1}$ for D-NC-S100 and D-NC-L100, respectively. The parameters $a$ and $b$ represent the amount of dissolved drug in the burst and sustained release phases, respectively. D-NC-S100 had higher values of desonide associated with the burst phase $a(a=68 \%$ and $b=31 \%)$ compared to D-NC-L100 ( $a=58 \%$ and $b=41 \%)$.

For the method using Franz diffusion cells (Figure 3), higher release control for D-LNC was obtained, while D-NCS100 and D-NC-L100 maintained a similar release profile. In this case, it can be seen that the encapsulation of desonide promoted better control of release compared with freedesonide, with faster drug release. Important to note that this experiment presented the lowest concentration release of desonide among employed release methods. Moreover, the presence of nanoparticles in the receptor compartment has not been verified, showing that nonintact nanoparticle was able to overtake the barrier of the cellulose acetate membrane, which could interfere with the results of in vitro release study.

All formulations presented the same model to describe the release profile obtained from dialysis sac; D-LNC and free-desonide were the monoexponential model (Table 5). D-LNC had higher release constants $\left(K=0.47 \mathrm{~h}^{-1}\right)$ than free-desonide $\left(K=0.40 \mathrm{~h}^{-1}\right)$ and half-life time $\left(t_{1 / 2}\right)$ was higher for free-desonide $(1.77 \mathrm{~h})$ than D-LNC $(1.51 \mathrm{~h})$. The biexponential model best described the release profile for D-NC-L100 and D-NC-S100, the concentrations of desonide associated with the burst $(a)$, and the sustained $(b)$ release phases ranged from 12 to $16 \%$ and from 83 to $87 \%$, respectively. D-NC-S100 had higher rate constants for both burst and sustained phases $\left(k_{1}=1.72 \mathrm{~h}\right.$ and $\left.k_{2}=0.013\right)$ compared to D-NC-L100 $\left(k_{1}=1.12 \mathrm{~h}\right.$ and $\left.k_{2}=0.006 \mathrm{~h}\right)$.

In order to investigate the release mechanism of desonide-loaded nanocapsule suspensions, the resultant data were fitted to the Korsmeyer-Peppas model. The $r$, MSC, and $n$ values are presented in Table 6. The accuracy of fit was evaluated by calculating correlation coefficient $(r)$; a satisfactory fit of the experimental data to the model was observed, through correlation coefficient near 1 . The $n$ 


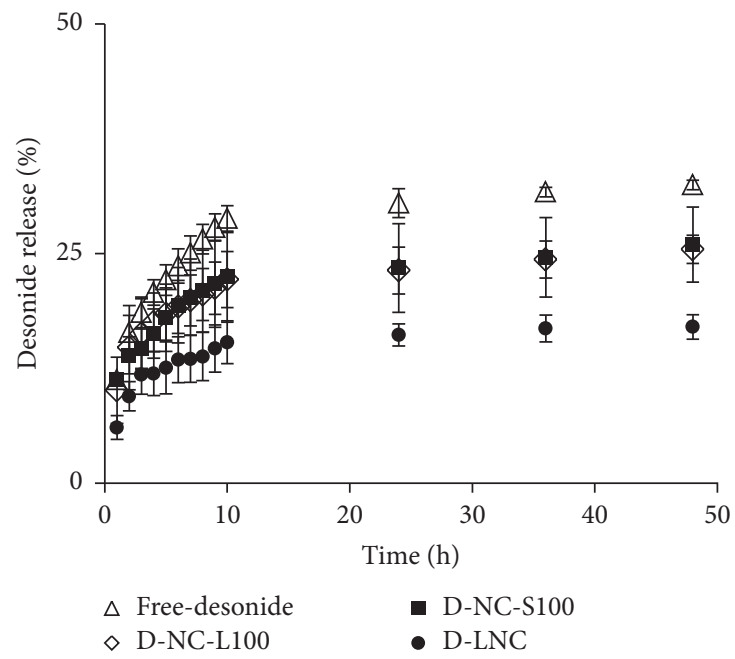

(a)

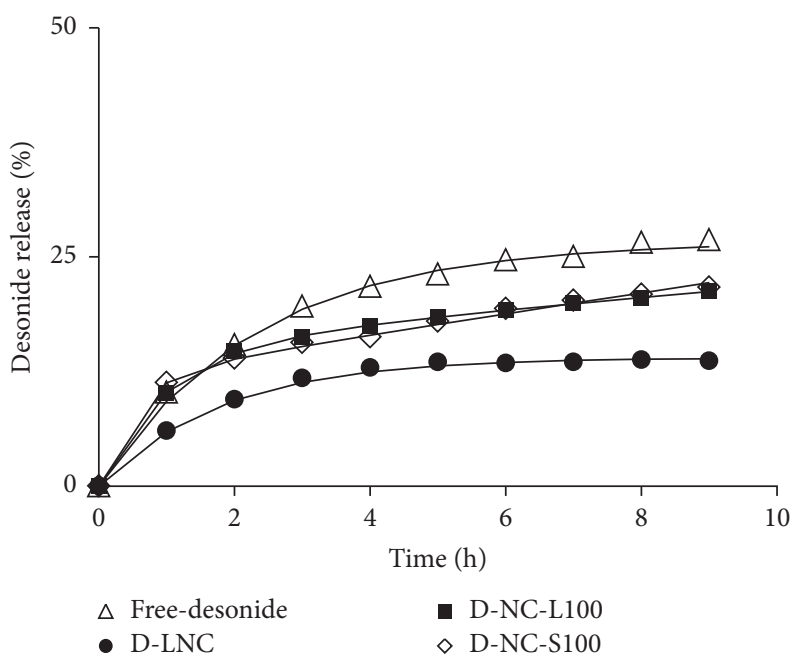

(b)

FIGURE 3: (a) Release profile of D-NC-S100, D-NC-L00, D-LNC, and free desonide using Franz diffusion cells. The scale of figures shown until $50 \%$. Statistical significance among D-LNC and D-NC-S100; D-LNC and free desonide; D-NC-L100 and free desonide (Tukey, $p<0.05$ ). (b) The lines correspond to the fitting to the monoexponential equation for D-LNC and free desonide, biexponential equation for D-NC-L100 and D-NC-S100.

TABLE 4: Release constants, correlation coefficients, and MSC obtained by fitting the release profiles of desonide using dialysis sac, according to the monoexponential and biexponential equations.

\begin{tabular}{lcccc}
\hline Equation & D-LNC & D-NC-S100 & D-NC-L100 & Free-desonide \\
\hline $\begin{array}{l}\text { Monoexponential } \\
\quad k\left(\mathrm{~h}^{-1}\right)\end{array}$ & $0.34 \pm 0.12$ & & & \\
$t_{1 / 2}(\mathrm{~h})$ & $2.06 \pm 0.40$ & $0.45 \pm 0.06$ & $0.6 \pm 0.08$ & $0.25 \pm 0.01$ \\
MSC & $4.68 \pm 0.82$ & $1.70 \pm 0.20$ & $1.16 \pm 0.16$ & $2.36 \pm 0.95$ \\
$r$ & $0.998 \pm 0.007$ & $4.55 \pm 0.73$ & $4.94 \pm 0.47$ & $4.51 \pm 0.66$ \\
Biexponential & & $0.996 \pm 0.004$ & $0.998 \pm 0.001$ & $0.995 \pm 0.002$ \\
$a$ & $0.41 \pm 0.09$ & & & \\
$K_{1}\left(\mathrm{~h}^{-1}\right)$ & $1.54 \pm 0.20$ & $0.68 \pm 0.09$ & $0.58 \pm 0.07$ & $0.52 \pm 0.15$ \\
$b$ & $0.59 \pm 0.07$ & $1.31 \pm 0.10$ & $1.62 \pm 0.45$ & $1.28 \pm 0.67$ \\
$K_{2}\left(\mathrm{~h}^{-1}\right)$ & $0.88 \pm 0.03$ & $0.31 \pm 0.05$ & $0.41 \pm 0.03$ & $0.46 \pm 0.22$ \\
MSC & $3.29 \pm 0.05$ & $0.03 \pm 0.01$ & $0.05 \pm 0.01$ & $0.06 \pm 0.03$ \\
$r$ & $0.991 \pm 0.006$ & $4.51 \pm 0.30$ & $4.18 \pm 0.77$ & $4.41 \pm 0.25$ \\
\hline
\end{tabular}

${ }^{*}$ Experiments were conducted with $n=5$.

values obtained from Korsmeyer-Peppas model obtained from dialysis sac method indicated diffusion controlled Fickian release for D-NC-L100 and D-NC-L100; already D-LNC showed non-Fickian (anomalous) release. On the other hand, the results obtained from Franz diffusion cells method indicated diffusion controlled Fickian release for all formulations.

In order to investigate what happens to the particle in drug release, studies used photon correlation spectroscopy (PCS) analysis to compare the particle size distribution profiles in the receptor medium over the time of drug release profile (Figure 4).

The results from dialysis sac method showed that the particle size of the D-NC-S100 and D-NC-L100 decreased over time, indicating weight loss of the polymer, suggesting an erosion process in the release of the drug. D-NC-S100, the process of release of desonide by erosion of the polymer chain, begins with ten minutes of the experiment and remains until the end $(72 \mathrm{~h})$, demonstrating that the erosion process starts before the first hour in the release of the drug. Already, for the D-NC-L100 the erosion process starts in the first hour and continues until tenth hour, showing drug release by diffusion followed erosion process after first hour. Moreover, after tenth hour it was not possible to experimentally determine the mean size, indicating the solubilization of polymer in release medium.

The dissolution method (Figure 5) was applied for not using membrane. Total release of desonide was observed in five hours; D-LNC obtained slower release than other formulations in this time (near $80 \%$ ). 
TABLE 5: Release constants, correlation coefficients, and MSC obtained by fitting the release profiles of desonide using dialysis sac, according to the monoexponential and biexponential equations.

\begin{tabular}{lcccc}
\hline Equation & D-LNC & D-NC-S100 & D-NC-L100 & Free-desonide \\
\hline Monoexponential & & & & \\
$\quad K\left(\mathrm{~h}^{-1}\right)$ & $0.47 \pm 0.09$ & $0.53 \pm 0.17$ & $0.76 \pm 0.19$ & $0.40 \pm 0.07$ \\
$t_{1 / 2}(\mathrm{~h})$ & $1.51 \pm 0.28$ & $1.38 \pm 0.21$ & $0.98 \pm 0.35$ & $1.77 \pm 0.29$ \\
MSC & $4.52 \pm 0.40$ & $2.93 \pm 0.39$ & $3.95 \pm 0.26$ & $4.21 \pm 0.76$ \\
$r$ & $0.997 \pm 0.002$ & $0.984 \pm 0.004$ & $0.995 \pm 0.003$ & \\
Biexponential & & & & \\
$a$ & $0.40 \pm 0.10$ & $0.16 \pm 0.01$ & $0.12 \pm 0.01$ & \\
$K_{1}\left(\mathrm{~h}^{-1}\right)$ & $0.34 \pm 0.08$ & $1.12 \pm 0.26$ & $1.72 \pm 0.07$ & \\
$b$ & $0.58 \pm 0.07$ & $0.83 \pm 0.03$ & $0.87 \pm 0.01$ & \\
$K_{2}\left(\mathrm{~h}^{-1}\right)$ & $0.27 \pm 0.05$ & $0.006 \pm 0.001$ & $0.013 \pm 0.004$ & $0.03 \pm 0.03$ \\
MSC & $4.21 \pm 0.36$ & $5.28 \pm 0.35$ & $4.90 \pm 0.36$ & $0.017 \pm 0.003$ \\
$r$ & $0.997 \pm 0.002$ & $0.998 \pm 0.001$ & $0.998 \pm 0.001$ & $5.14 \pm 0.22$ \\
\hline
\end{tabular}

* Experiments were conducted with $n=5$.

TABLE 6: Correlation coefficient $(r)$, model selection criteria (MSC), and release exponent $(n)$ obtained by fitting the release profiles of desonide according to the Korsmeyer-Peppas equation.

\begin{tabular}{lcccc}
\hline & D-LNC & D-NC-S100 & D-NC-L100 & Free-desonide \\
\hline Dialysis sac & & & & \\
$\quad n$ & $0.47 \pm 0.03$ & $0.33 \pm 0.04$ & $0.30 \pm 0.03$ & $0.50 \pm 0.11$ \\
MSC & $3.63 \pm 0.25$ & $4.24 \pm 0.16$ & $3.89 \pm 0.64$ & $4.19 \pm 0.49$ \\
$r$ & $0.998 \pm 0.004$ & $0.993 \pm 0.003$ & $0.997 \pm 0.002$ & $0.992 \pm 0.004$ \\
Franz cells & & & & \\
$\quad n$ & $0.28 \pm 0.07$ & $0.25 \pm 0.07$ & $0.29 \pm 0.07$ & $0.37 \pm 0.04$ \\
MSC & $3.25 \pm 0.38$ & $4.77 \pm 0.54$ & $4.04 \pm 0.36$ & $4.78 \pm 0.64$ \\
$r$ & $0.995 \pm 0.05$ & $0.996 \pm 0.002$ & $0.996 \pm 0.003$ & $0.996 \pm 0.001$ \\
\hline
\end{tabular}

${ }^{*}$ Experiments were conducted with $n=5$.

Due to absence of membrane in the dissolution method, the drug is rapidly released from the nanoparticles, not being possible to study the kinetics of drug release using mathematical models.

\section{Discussion}

Desonide has no inclusion in any pharmacopoeia [55]; however the determination of desonide in biological samples had already been performed by HPLC $[56,57]$, as well as ear drops [58], lotion hair [55,59], creams, and ointments $[49,60]$, but never was encapsulated or quantified in nanoparticles. These colloidal drug carrier systems such as nanocapsules are analytical challenge due to the variety of compounds in the formulation and also the need to detect small amounts of drugs [61]. Therefore the importance of the results obtained in this work is due to not only the quantification of desonide but also mostly the quantification of this drug in a colloidal vehicle.

Comparing the quantification of D-LNC with ointment [62] is possible to realize that using the same mobile phase the peak of desonide came out in 7.9 min later obtained in the ointment which was around $4.0 \mathrm{~min}$. However, ointment which indicates the presence of two peaks degradation products of desonide in times 1.0 and $2.0 \mathrm{~min}$; probably the lipidcore nanocapsules provided protection from degradation. Santa et al. [55] method was developed to quantify desonide in hair lotion using the different mobile phase but showed the peak of drug in the time similar to ours (around 8.5 minutes).

Desonide-loaded nanocapsule suspensions used in this study prepared with different polymers had mean diameter and polydispersity index values in accordance with that expected for these systems $[16,20]$. The type and concentration of the polymer are crucial to the particle size [11, 63]. The nanocapsules obtained from the PCL polymer showed larger particle diameter than the nanoparticles with Eudragit polymers, according to result as reported by Leroux et al. [64]. The zeta potential values for nanocapsules are a consequence of the particle coating with presence of nonionic species with long hydrophilic chain, such as polysorbate 80 acting as a physical stabilizer at the particle/water interface [65]. These formulations were sterically stabilized by the polysorbate layer around the particles, guaranteed by the interaction of hydrophilic chains [26, 65]. All formulations showed acid $\mathrm{pH}$ values, in agreement with previous studies $[44,66,67]$. The formulations presented encapsulation efficiency (E.E) higher than $90 \%$ (values between 91.0 and 98.8\%). According 


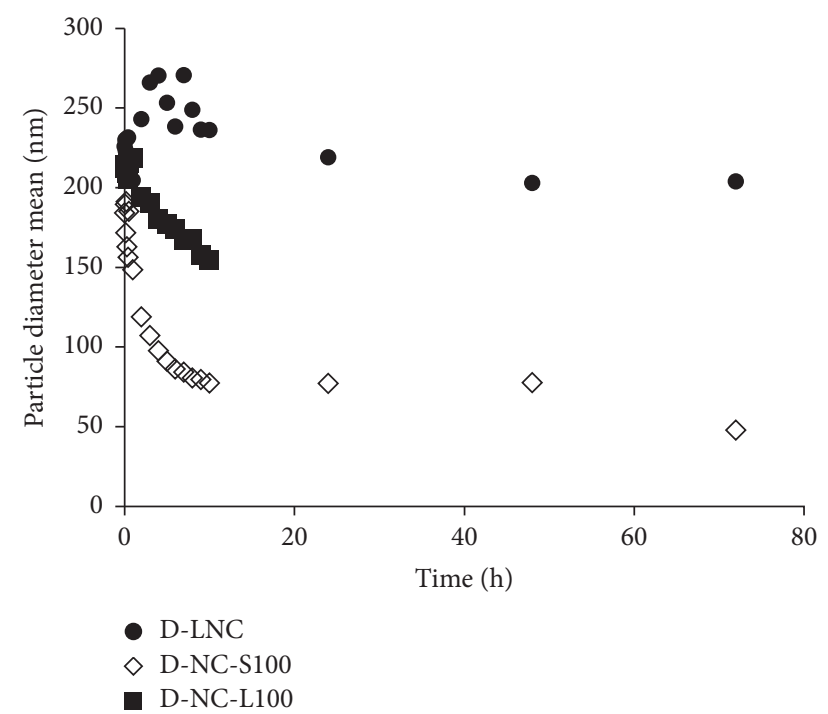

Figure 4: Particle size distribution over the time of drug release profile from dialysis sac method.

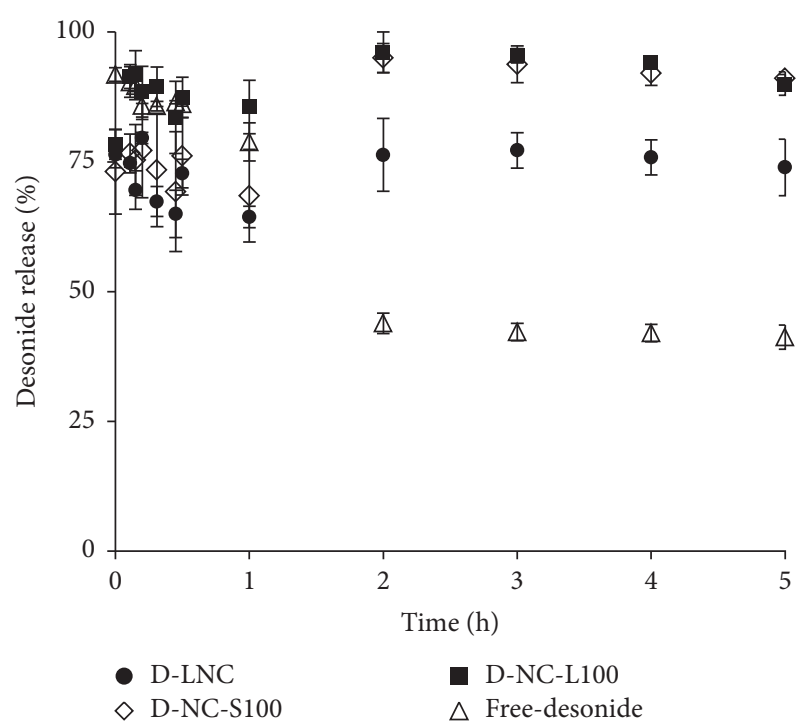

Figure 5: Release profile of D-NC-S100, D-NC-L100, D-LNC, and free-desonide using dissolution method. Statistical significance among D-NC-L100 and free-desonide (Tukey, $p<0.05$ ).

to Mora-Huertas et al. [22], various parameters with drug, polymer, oil, and nanocapsule preparation method are determinant factors of drug encapsulation efficiency. Besides that, no nanocrystal was formed in formulations, indicating that the drug is adsorbed on the nanocapsules, but the system is not oversaturated and the formulation is stable [52].

Drug release from nanoparticles depends on diffusion, particle erosion, or the combination of these [68]. The maintaining the sink condition is a crucial requirement for in vitro drug release studies in the pharmaceutical field; this condition determines that drug concentration in the dissolution or release medium may not exceed 10 to $33 \%$ of drug solubility in these mediums [40]. Due to the very low aqueous solubility drugs, these special techniques to study the release from nanoparticles under sink conditions too need very sensitive methods for drug quantification [69].

Incomplete release of desonide from nanocapsules could be attributed to the retention capacity of the polymer, as described with indomethacin-loaded nanocapsules [70], primidone-loaded nanocapsules [71], and atovaquone-loaded nanocapsules with different polymers [23]. However, desonide presented $90 \%$ release from dissolution method after $2 \mathrm{~h}$ for all the formulations tested, demonstrating a limitation of technique previously tested. Result of agreement with Marchais et al. [46] showed that the release of phenylbutazoneloaded nanocapsules from different polyesters is affected by the type of polymer and the experimental conditions. Dissolution study was already described for determination of release from the nanoparticles by Zili et al. [72].

In relation to methodologies using membranes (dialysis and Franz) which are more used with nanocapsules, different results were found that can be attributed to experimental conditions. Moreover, de Andrade et al. [45] demonstrated the importance of the choice of the synthetic membrane using the Franz diffusion cells technique. The dialysis membrane $(12 \mathrm{kDa}$ pore size) was suggested as the best choice for this kind of experiment, in comparison with polycarbonate $(0.05 \mu \mathrm{m})$ or cellulose acetate $(0.45 \mu \mathrm{m})$ membranes, because it has a limiting barrier for nanocapsules. In addition, control release presented by free desonide using dialysis sac method can be explained due to the use sorbitan monostearate in preparation. Yoshioka et al. [73] showed that release from vesicles depended on the surfactant used in the preparation. Furthermore, it was demonstrated that increase in the sorbitan monostearate concentration increased the resistance to the drug diffusion in nanoparticle [20].

In all methodologies, D-NC-L100 resulted in the faster release of desonide between nanocapsule suspensions, which can be attributed to $\mathrm{pH}$-dependent solubility of polymer Eudragit L100 [33]. This polymer is soluble in $\mathrm{pH} 6$ and release medium used $\mathrm{pH} 5.5$, therefore near the $\mathrm{pH}$ value that it is soluble.

In all methodologies, D-NC-L100 with diameter lower particle resulted in the faster release of desonide between nanocapsule suspensions, as described by Zili et al. [72] who showed that nanoparticle size can influence the nanocapsule dissolution rate which increases as particle size decreases, due to an increase of available surface area.

The models that described the release profile were equal regardless of the release method used. D-LNC and freedesonide were monoexponential model and, D-NC-L100 and D-NC-S100 were biexponential model. This result is in agreement with previous research, where drug release from nanocapsules was according to a monoexponential or biexponential model $[20,26,30]$.

Drug release kinetics of desonide-loaded nanocapsule suspensions were analyzed using Korsmeyer-Peppas model and showing Fickian diffusion for all suspensions obtained by Franz diffusion cells method. However, the study for determining the particle diameter over the time of drug 
release showed a reduction in particle diameter for DNC-S100 and D-NC-L100 indicating occurrence of erosion process in the desonide release. Dialysis sac method showed non-Fickian (anomalous) release for D-LNC, in which the mass transfer occurs due to the drug Fickian diffusion and the relaxation of the polymer chains [53]. However, in this case no change in the particle diameter was observed.

\section{Conclusions}

Desonide-loaded nanocapsule suspensions prepared with PCL, Eudragit L100, or Eudragit S100 showed good physicochemical properties. The analytical method for the quantification of D-LNC was validated in the range of 2.5 to $15.0 \mu \mathrm{g} / \mathrm{mL}$. The method specificity, linearity, precision, and accuracy were validated and considered adequate. The type of the polymer and in vitro methods for desonide release influenced the result obtained and in vitro drug-model release from formulations showed monoexponential (D-LNC and free desonide) and biexponential (D-NC-L100 and D-NCS100) release profile, regardless of the type of drug release method. Therefore, we demonstrated that Korsmeyer-Peppas model did not succeed to determine the mechanism of desonide release from nanocapsule suspensions.

\section{Competing Interests}

The authors declare no conflict of interests regarding this article content.

\section{Acknowledgments}

M. B. Antonow thanks CAPES-Brazil for his Master Fellowship. The authors thank the financial support of CAPES, CNPq, and FAPERGS.

\section{References}

[1] J. Iqbal, A. Husain, and A. Gupta, "Photochemistry of desonide, a non-fluorinated steroidal anti-inflammatory drug," Chemical and Pharmaceutical Bulletin, vol. 54, no. 6, pp. 836-838, 2006.

[2] L. H. Kircik, "Treatment of scalp and facial seborrheic dermatitis with desonide hydrogel 0.05\%," Journal of Clinical and Aesthetic Dermatology, vol. 2, no. 2, pp. 32-36, 2009.

[3] U. R. Hengge, T. Ruzicka, R. A. Schwartz, and M. J. Cork, "Adverse effects of topical glucocorticosteroids," Journal of the American Academy of Dermatology, vol. 54, no. 1, pp. 1-15, 2006.

[4] B. Elewski, "An investigator-blind, randomized, 4-week, parallel-group, multicenter pilot study to compare the safety and efficacy of a nonsteroidal cream (Promiseb Topical Cream) and desonide cream $0.05 \%$ in the twice-daily treatment of mild to moderate seborrheic dermatitis of the face," Clinics in Dermatology, vol. 27, no. 6, pp. S48-S53, 2009.

[5] N. Rocha, M. Horta, and M. Selores, “Terapêutica tópica em dermatologia pediátrica," Revista Nascer e Crescer, vol. 13, no. 3, pp. 215-225, 2004.

[6] A. D. Costa, S. Machado, and M. Selores, "Corticóides tópicos considerações sobre a sua aplicação na patologia cutânea,"
Revista Portuguesa de Medicina Geral e Familiar, vol. 21, pp. 367-373, 2005.

[7] P. S. Grau, "Corticoides tópicos. Actualización," Medicina Cutánea Ibero-Latino-Americana, vol. 34, no. 1, pp. 33-38, 2006.

[8] S. Bamrungsap, Z. Zhao, T. Chen et al., "Nanotechnology in therapeutics: a focus on nanoparticles as a drug delivery system," Nanomedicine, vol. 7, no. 8, pp. 1253-1271, 2012.

[9] P. Couvreur, G. Barratt, E. Fattal, P. Legrand, and C. Vauthier, "Nanocapsule technology: a review," Critical Reviews in Therapeutic Drug Carrier Systems, vol. 19, no. 2, pp. 99-134, 2002.

[10] J. A. Champion, Y. K. Katare, and S. Mitragotri, "Particle shape: a new design parameter for micro- and nanoscale drug delivery carriers," Journal of Controlled Release, vol. 121, no. 1-2, pp. 3-9, 2007.

[11] M. C. Fontana, K. Coradini, A. R. Pohlmann, S. S. Guterres, and R. C. R. Beck, "Nanocapsules prepared from amorphous polyesters: effect on the physicochemical characteristics, drug release, and photostability," Journal of Nanoscience and Nanotechnology, vol. 10, no. 5, pp. 3091-3099, 2010.

[12] J. Kreuter, Colloidal Drug Delivery Systems, Marcel Dekker, New York, NY, USA, 1994.

[13] A. Bernardi, A. A. C. C. V. Zilberstein, E. Jäger et al., "Effects of indomethacin-loaded nanocapsules in experimental models of inflammation in rats," British Journal of Pharmacology, vol. 158, no. 4, pp. 1104-1111, 2009.

[14] C. F. Alves, N. F. S. de Mello, L. F. Fraceto et al., "Effects of 15d-PGJ ${ }_{2}$-loaded poly(D,L-lactide-co-glycolide) nanocapsules on inflammation," British Journal of Pharmacology, vol. 162, no. 3, pp. 623-632, 2011.

[15] R. B. Friedrich, M. C. Fontana, R. C. R. Beck, A. R. Pohlmann, and S. S. Guterres, "Development and physicochemical characterization of dexamethasone-loaded polymeric nanocapsule suspensions," Química Nova, vol. 31, no. 5, pp. 1131-1136, 2008.

[16] M. C. Fontana, K. Coradini, S. S. Guterres, A. R. Pohlmann, and R. C. R. Beck, "Nanoencapsulation as a way to control the release and to increase the photostability of clobetasol propionate: influence of the nanostructured system," Journal of Biomedical Nanotechnology, vol. 5, no. 3, pp. 254-263, 2009.

[17] T. Ishihara, M. Takahashi, M. Higaki, and Y. Mizushima, "Efficient encapsulation of a water-soluble corticosteroid in biodegradable nanoparticles," International Journal of Pharmaceutics, vol. 365, no. 1-2, pp. 200-205, 2009.

[18] L. B. Jensen, E. Magnussson, L. Gunnarsson, C. Vermehren, H. M. Nielsen, and K. Petersson, "Corticosteroid solubility and lipid polarity control release from solid lipid nanoparticles," International Journal of Pharmaceutics, vol. 390, no. 1, pp. 5360, 2010.

[19] J. Zhang and E. Smith, "Percutaneous permeation of betamethasone 17-valerate incorporated in lipid nanoparticles," Journal of Pharmaceutical Sciences, vol. 100, no. 3, pp. 896-903, 2011.

[20] E. Jäger, C. G. Venturini, F. S. Poletto et al., "Sustained release from lipid-core nanocapsules by varying the core viscosity and the particle surface area," Journal of Biomedical Nanotechnology, vol. 5, no. 1, pp. 130-140, 2009.

[21] F. S. Poletto, E. Jäger, L. Cruz, A. R. Pohlmann, and S. S. Guterres, "The effect of polymeric wall on the permeability of drug-loaded nanocapsules," Materials Science and Engineering: C, vol. 28, no. 4, pp. 472-478, 2008.

[22] C. E. Mora-Huertas, H. Fessi, and A. Elaissari, "Polymerbased nanocapsules for drug delivery," International Journal of Pharmaceutics, vol. 385, no. 1-2, pp. 113-142, 2010. 
[23] E. Cauchetier, M. Deniau, H. Fessi, A. Astier, and M. Paul, "Atovaquone-loaded nanocapsules: influence of the nature of the polymer on their in vitro characteristics," International Journal of Pharmaceutics, vol. 250, no. 1, pp. 273-281, 2003.

[24] A. R. Pohlmann, V. Weiss, O. Mertins, N. Pesce da Silveira, and S. Stanisçuaski Guterres, "Spray-dried indomethacin-loaded polyester nanocapsules and nanospheres: development, stability evaluation and nanostructure models," European Journal of Pharmaceutical Sciences, vol. 16, no. 4-5, pp. 305-312, 2002.

[25] L. Cruz, L. U. Soares, T. D. Costa et al., "Diffusion and mathematical modeling of release profiles from nanocarriers," International Journal of Pharmaceutics, vol. 313, no. 1-2, pp. 198205, 2006.

[26] L. M. Rigo, V. Frescura, L. Fiel et al., "Influence of the type of vegetable oil on the drug release profile from lipid-core nanocapsules and in vivo genotoxicity study," Pharmaceutical Development and Technology, vol. 19, no. 7, pp. 789-798, 2014.

[27] R. B. Friedrich, B. Kann, K. Coradini, H. L. Offerhaus, R. C. R. Beck, and M. Windbergs, "Skin penetration behavior of lipidcore nanocapsules for simultaneous delivery of resveratrol and curcumin," European Journal of Pharmaceutical Sciences, vol. 78, pp. 204-213, 2015.

[28] S. R. Schaffazick, I. R. Siqueira, A. S. Badejo et al., "Incorporation in polymeric nanocapsules improves the antioxidant effect of melatonin against lipid peroxidation in mice brain and liver," European Journal of Pharmaceutics and Biopharmaceutics, vol. 69, no. 1, pp. 64-71, 2008.

[29] T. Nassar, A. Rom, A. Nyska, and S. Benita, "Novel double coated nanocapsules for intestinal delivery and enhanced oral bioavailability of tacrolimus, a P-gp substrate drug," Journal of Controlled Release, vol. 133, no. 1, pp. 77-84, 2009.

[30] R. V. Contri, T. Katzer, A. R. Pohlmann, and S. S. Guterres, "Chitosan hydrogel containing capsaicinoids-loaded nanocapsules: an innovative formulation for topical delivery," Soft Materials, vol. 8, no. 4, pp. 370-385, 2010.

[31] Y. Lu and S. C. Chen, "Micro and nano-fabrication of biodegradable polymers for drug delivery," Advanced Drug Delivery Reviews, vol. 56, no. 11, pp. 1621-1633, 2004.

[32] L. S. Nair and C. T. Laurencin, "Biodegradable polymers as biomaterials," Progress in Polymer Science, vol. 32, no. 8-9, pp. 762-798, 2007.

[33] K. Animesh, M. Afrasim, R. R. Bommareddy, A. Ayaz, R. Shruthi, and H. G. Shivakumar, "Applicability and approaches of (Meth) acrylate copolymers (Eudragits) in novel drug delivery systems," Current Drug Therapy, vol. 7, no. 4, pp. 219-234, 2012.

[34] C. G. Venturini, E. Jäger, C. P. Oliveira et al., "Formulation of lipid core nanocapsules," Colloids and Surfaces A: Physicochemical and Engineering Aspects, vol. 375, no. 1-3, pp. 200-208, 2011.

[35] T. L. de Brum, L. A. Fiel, R. V. Contri, S. S. Guterres, and A. R. Pohlmann, "Polymeric nanocapsules and lipid-core nanocapsules have diverse skin penetration," Journal of Nanoscience and Nanotechnology, vol. 15, no. 1, pp. 773-780, 2015.

[36] A. Melero, A. F. Ourique, S. S. Guterres et al., "Nanoencapsulation in lipid-core nanocapsules controls mometasone furoate skin permeability rate and its penetration to the deeper skin layers," Skin Pharmacology and Physiology, vol. 27, no. 4, pp. 217228, 2014.

[37] T. C. Beber, D. F. de Andrade, P. dos Santos Chaves, A. R. Pohlmann, S. S. Guterres, and R. C. Beck, "Cationic polymeric nanocapsules as a strategy to target dexamethasone to viable epidermis: skin penetration and permeation studies," Journal of
Nanoscience and Nanotechnology, vol. 16, no. 2, pp. 1331-1338, 2016.

[38] A. L. Savian, D. Rodrigues, J. Weber et al., "Dithranol-loaded lipid-core nanocapsules improve the photostability and reduce the in vitro irritation potential of this drug," Materials Science and Engineering C, vol. 46, pp. 69-76, 2015.

[39] J. Weber, N. L. Funk, M. H. Motta et al., "Association of borage oil and betamethasone dipropionate in lipid-core nanocapsules: characterization, photostability and in vitro irritation test," Journal of Nanoscience and Nanotechnology, vol. 16, no. 2, pp. 1354-1362, 2016.

[40] D. F. de Andrade, C. Zuglianello, A. R. Pohlmann, S. S. Guterres, and R. C. R. Beck, "Assessing the in vitro drug release from lipidcore nanocapsules: a new strategy combining dialysis sac and a continuous-flow system," AAPS PharmSciTech, vol. 16, no. 6, pp. 1409-1417, 2015.

[41] A. R. da Silva, E. D. Zaniquelli, M. O. Baratti et al., "Drug release from microspheres and nanospheres of poly(lactideco-glycolide) without sphere separation from release médium," Journal Of The Brazilian Chemical Society, vol. 21, no. 2, pp. 214$225,2010$.

[42] X. Xu, M. A. Khan, and D. J. Burgess, "A two-stage reverse dialysis in vitro dissolution testing method for passive targeted liposomes," International Journal of Pharmaceutics, vol. 426, no. 1-2, pp. 211-218, 2012.

[43] R. C. R. Beck, A. R. Pohlmann, C. Hoffmeister et al., "Dexamethasone-loaded nanoparticle-coated microparticles: correlation between in vitro drug release and drug transport across Caco-2 cell monolayers," European Journal of Pharmaceutics and Biopharmaceutics, vol. 67, no. 1, pp. 18-30, 2007.

[44] J. S. Almeida, F. Lima, S. D. Ros, L. O. S. Bulhões, L. M. de Carvalho, and R. C. R. Beck, "Nanostructured systems containing rutin: in vitro antioxidant activity and photostability studies," Nanoscale Research Letters, vol. 5, no. 10, pp. 1603-1610, 2010.

[45] D. F. de Andrade, M. C. Fontana, and R. C. R. Beck, "Evaluation of three synthetic membranes as limiting barrier for in vitro drug release studies from hydrogels containing polymeric nanocapsules," Current Nanoscience, vol. 10, no. 3, pp. 367-373, 2014.

[46] H. Marchais, S. Benali, J. M. Irache, C. Tharasse-Bloch, O. Lafont, and A. M. Orecchioni, "Entrapment efficiency and initial release of phenylbutazone from nanocapsules prepared from different polyesters," Drug Development and Industrial Pharmacy, vol. 24, no. 9, pp. 883-888, 1998.

[47] S. S. Guterres, M. P. Alves, and A. R. Pohlmann, "Polymeric nanoparticles, nanospheres and nanocapsules, for cutaneous applications," Drug Target Insights, vol. 2, pp. 147-157, 2007.

[48] H. Fessi, F. Puisieux, and J. P. de Vissaguet, "Procédé de préparation de systèmes colloidaux dispersibles d'une substance, sous forme de nanocapsules," European Patent 0274961 A1, 1988.

[49] T. T. Nguyen, R. Kringstad, and K. E. Rasmussen, "Use of extraction columns for the isolation of desonide and parabens from creams and ointments for high-performance liquid chromatographic analysis," Journal of Chromatography A, vol. 366, pp. $445-450,1986$.

[50] International Conference on Harmonization (ICH), Validation of Analytical Procedures: Text and Methodology Q2(R1), 2005.

[51] C. P. Oliveira, C. G. Venturini, B. Donida, F. S. Poletto, S. S. Guterres, and A. R. Pohlmann, "An algorithm to determine 
the mechanism of drug distribution in lipid-core nanocapsule formulations," Soft Matter, vol. 9, no. 4, pp. 1141-1150, 2013.

[52] A. R. Pohlmann, G. Mezzalira, C. D. G. Venturini et al., "Determining the simultaneous presence of drug nanocrystals in drug-loaded polymeric nanocapsule aqueous suspensions: a relation between light scattering and drug content," International Journal of Pharmaceutics, vol. 359, no. 1-2, pp. 288-293, 2008.

[53] R. W. Korsmeyer, R. Gurny, E. Doelker, P. Buri, and N. A. Peppas, "Mechanisms of solute release from porous hydrophilic polymers," International Journal of Pharmaceutics, vol. 15, no. 1, pp. 25-35, 1983.

[54] N. H. Maniya, S. R. Patel, and Z. V. P. Murthy, "Controlled delivery of acyclovir from porous silicon micro- and nanoparticles," Applied Surface Science, vol. 330, pp. 358-365, 2015.

[55] F. D. Santa, L. E. Sperotto, M. P. Braga et al., "Development and validation of a simple stability-indicating LC-method and UVA photostability study of desonide hair lotion," Current Analytical Chemistry, vol. 9, no. 4, pp. 659-667, 2013.

[56] A. Vonaparti, E. Lyris, I. Panderi, M. Koupparis, and C. Georgakopoulos, "Direct injection LC/ESI-MS horse urine analysis for the quantification and identification of threshold substances for doping control. I. Determination of hydrocortisone," Journal of Mass Spectrometry, vol. 43, no. 9, pp. 1255-1264, 2008.

[57] E. Tudela, G. Muñoz, and J. A. Muñoz-Guerra, "Matrix effect marker for multianalyte analysis by LC-MS/MS in biological samples," Journal of Chromatography B, vol. 901, pp. 98-106, 2012.

[58] V. D. Gupta, "Chemical stability of desonide in ear drops," International Journal of Pharmaceutical Compounding, vol. 11, no. 1, pp. 79-81, 2007.

[59] P. Rosa, A. P. S. Salla, C. D. B. da Silva, C. M. B. Rolim, and A. I. H. Adams, "Investigation of the stabilizing effects of antioxidants and benzophenone-3 on desonide photostability," AAPS PharmSciTech, vol. 15, no. 5, pp. 1155-1162, 2014.

[60] A. M. di Pietra, V. Andrisano, R. Gotti, and V. Cavrini, "On-line post-column photochemical derivatization in liquid chromatographic-diode-array detection analysis of binary drug mixtures," Journal of Pharmaceutical and Biomedical Analysis, vol. 14, no. 8-10, pp. 1191-1199, 1996.

[61] G. D. Tavares, G. M. Ishikawa, T. F. Monteiro et al., "Derivative spectrophotometric method for determination of acyclovir in polymeric nanoparticles," Quimica Nova, vol. 35, no. 1, pp. 203206, 2012.

[62] T. T. Nguyen, R. Kringstad, A. J. Aasen, and K. E. Rasmussen, "Identification and analysis of a degradation product of the glucocorticoid desonide in ointment," Acta Chemica Scandinavica, Series B: Organic Chemistry and Biochemistry, vol. 42, no. 6, pp. 403-407, 1988.

[63] D. Quintanar-Guerrero, E. Allémann, H. Fessi et al., "Preparation and characterization of nanocapsules from preformed polymers by a new process based on emulsification-diffusion technique," Drug Development and Industrial Pharmacy, vol. 24, pp. 1113-1128, 1998.

[64] J.-C. Leroux, E. Allémann, E. Doelker, and R. Gurny, "New approach for the preparation of nanoparticles by an emulsification-diffusion method," European Journal of Pharmaceutics and Biopharmaceutics, vol. 41, no. 1, pp. 14-18, 1995.

[65] L. A. Fiel, M. D. Adorne, S. S. Guterres, P. A. Netz, and A. R. Pohlmann, "Variable temperature multiple light scattering analysis to determine the enthalpic term of a reversible agglomeration in submicrometric colloidal formulations: a quick quantitative comparison of the relative physical stability," Colloids and Surfaces A, vol. 431, pp. 93-104, 2013.

[66] S. R. Schaffazick, S. S. Guterres, L. D. Freitas, and A. R. Pohlmann, "Caracterização e estabilidade físico-química de sistemas poliméricos nanoparticulados para administração de fármacos," Química Nova, vol. 26, no. 5, pp. 726-737, 2003.

[67] S. R. Schaffazick, A. R. Pohlmann, G. Mezzaliraa, and S. S. Guterres, "Development of nanocapsule suspensions and nanocapsule spray-dried powders containing melatonin," Journal of the Brazilian Chemical Society, vol. 17, no. 3, pp. 562-569, 2006.

[68] K. S. Soppimath, T. M. Aminabhavi, A. R. Kulkarni, and W. E. Rudzinski, "Biodegradable polymeric nanoparticles as drug delivery devices," Journal of Controlled Release, vol. 70, no. 1-2, pp. 1-20, 2001.

[69] R. T. Branquinho, V. C. F. Mosqueira, E. K. Kano et al., "HPLC$\mathrm{DAD}$ and UV-spectrophotometry for the determination of lychnopholide in nanocapsule dosage form: validation and application to release kinetic study," Journal of Chromatographic Science, vol. 52, no. 1, pp. 19-26, 2014.

[70] N. Ammoury, H. Fessi, J. P. Devissaguet, F. Puisieux, and S. Benita, "In vitro release kinetic pattern of indomethacin from poly(D,L-lactide) nanocapsules," Journal of Pharmaceutical Sciences, vol. 79, no. 9, pp. 763-767, 1990.

[71] V. Ferranti, H. Marchais, C. Chabenat, A. M. Orecchioni, and O. Lafont, "Primidone-loaded poly- $\varepsilon$-caprolactone nanocapsules: incorporation efficiency and in vitro release profiles," International Journal of Pharmaceutics, vol. 193, no. 1, pp. 107-111, 1999.

[72] Z. Zili, S. Sfar, and H. Fessi, "Preparation and characterization of poly- $\varepsilon$-caprolactone nanoparticles containing griseofulvin," International Journal of Pharmaceutics, vol. 294, no. 1-2, pp. 261267, 2005.

[73] T. Yoshioka, B. Sternberg, and A. T. Florence, "Preparation and properties of vesicles (niosomes) of sorbitan monoesters (Span 20, 40, 60 and 80) and a sorbitan triester (Span 85)," International Journal of Pharmaceutics, vol. 105, no. 1, pp. 1-6, 1994. 

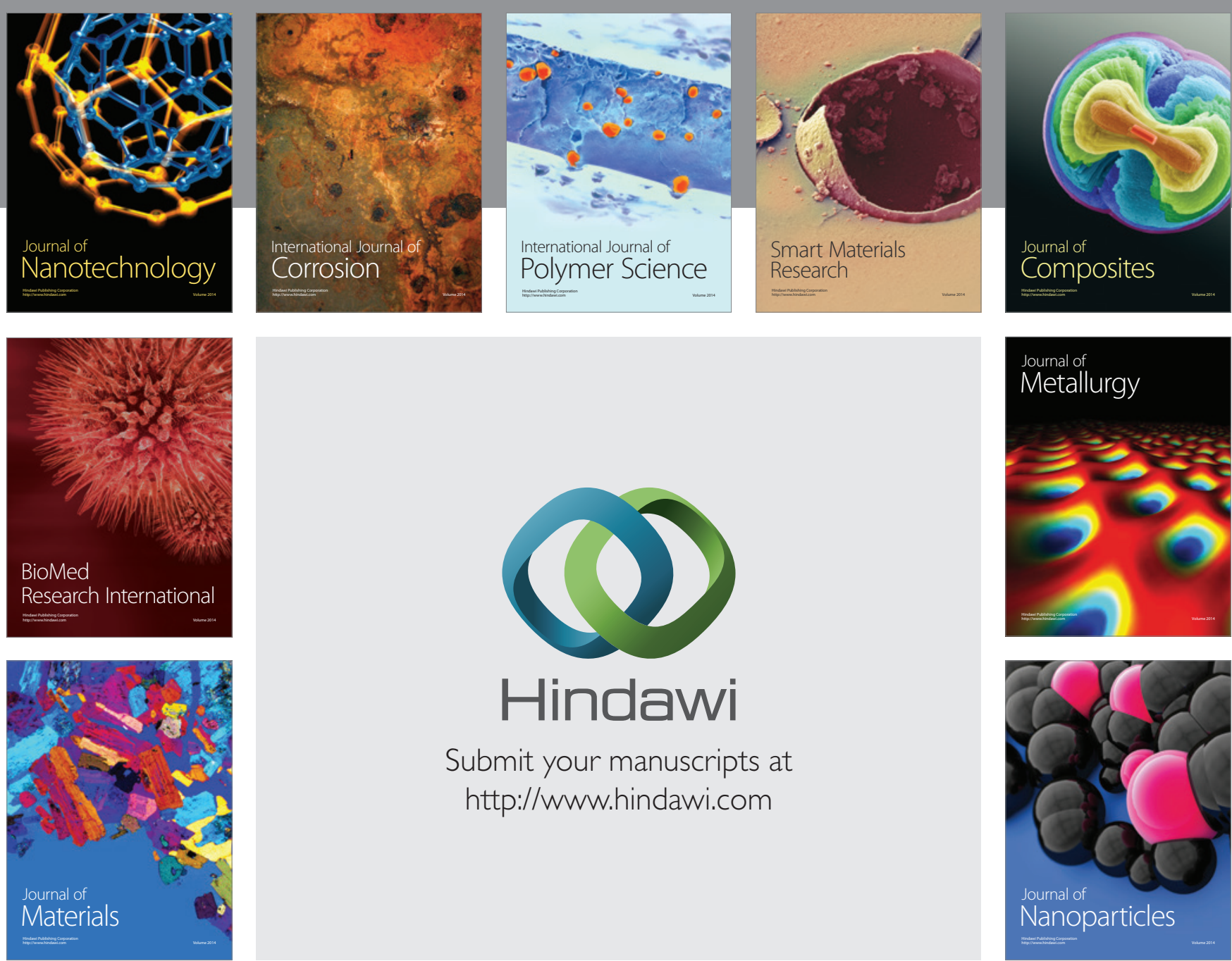

\section{Hindawi}

Submit your manuscripts at

http://www.hindawi.com

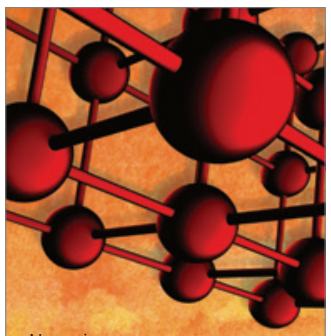

Materials Science and Engineering
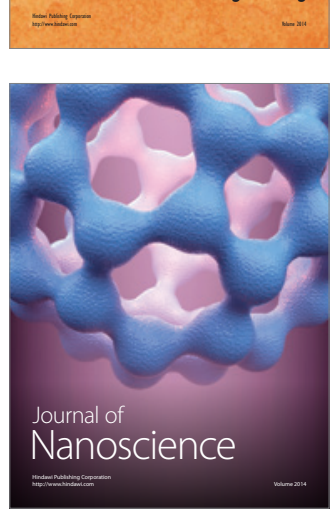
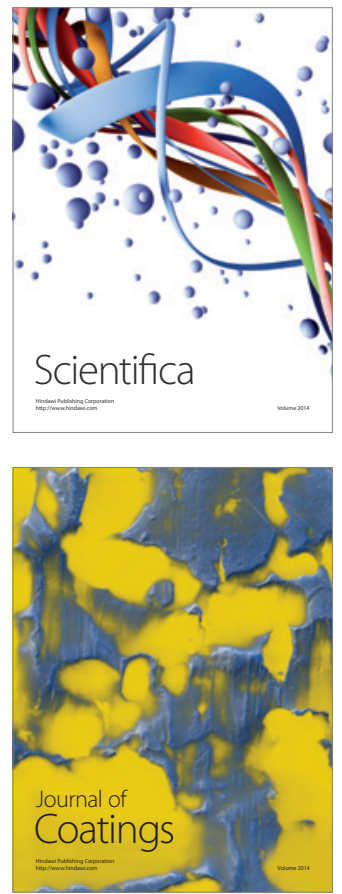
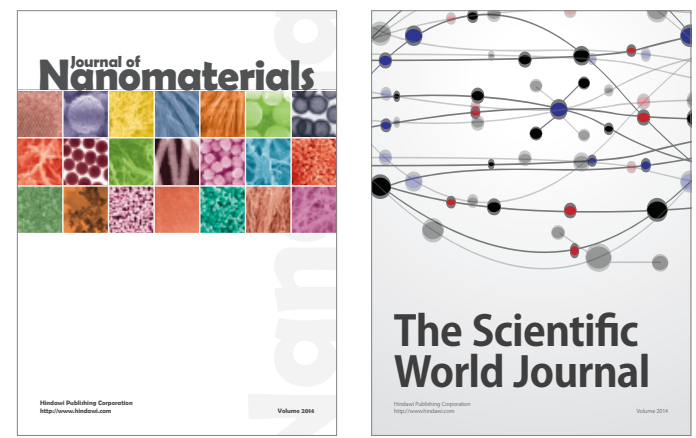

The Scientific World Journal
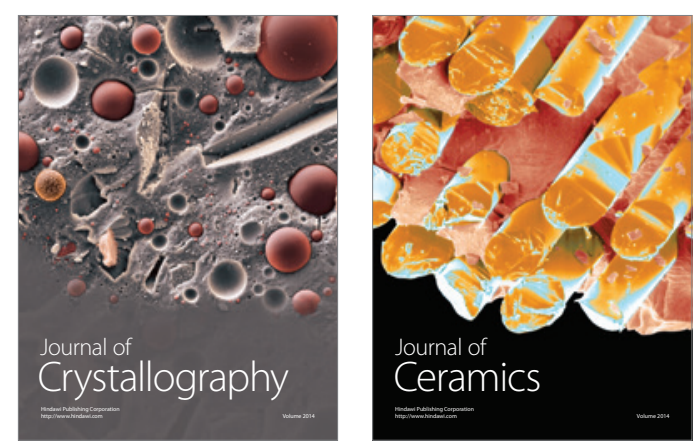
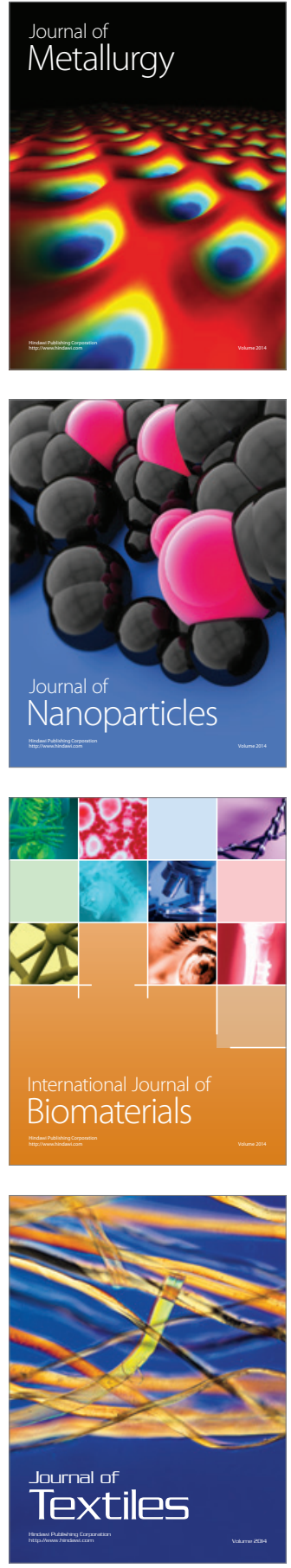